\title{
Application of Bone Marrow-Derived Mesenchymal Stem Cells in the Treatment of Intrauterine Adhesions in Rats
}

\author{
Jianmei Wang Baohui Ju Caijun Pan Yan Gu Yu Zhang Li Sun Bumei Zhang \\ Yujuan Zhang
}

Department of Family Planning, The Second Hospital of Tianjin Medical University, Tianjin, China

\section{Key Words}

Intrauterine adhesion - Bone marrow mesenchymal stem cells - Estrogen Receptor • Progesterone Receptor

\begin{abstract}
Aims: To investigate the therapeutic effects of bone marrow-derived mesenchymal stem cells (BMSCs) transplantation on intrauterine adhesions (IUA). Methods: BMSCs were isolated and labeled by green fluorescence protein. IUA model was established by mechanical injury. 48 rats were randomly divided into control, IUA model, BMSCs vein injection and BMSCs intrauterine injection groups ( $n=12$ in each group). The third generation of BMSCs was injected through tail vein or intrauterine. Three rats were killed at time $0 \mathrm{~h}, 7 \mathrm{~d}, 14 \mathrm{~d}$ and $28 \mathrm{~d}$ and bilateral uterus were obtained at each time points for the subseqent experiments. Morphological changes were determined by hematoxylin-eosin staining or Masson staining. Estrogen receptor (ER) and progesterone receptor (PR) were detected by immunohistochemistry. Results: BMSCs were specifically stained by CD44 and CD90, but not by CD45. Before treatment, the numbers of endometrial glands were significantly decreased, while fibrosis area rate was increased in IUA model group ( $\mathrm{P}<0.05$ vs Control). Meanwhile, ER expression, but not PR was significantly up-regulated in model group $(\mathrm{P}<0.05$ vs Control). By contrast, the therapies by BMSCs transplantation through either tail vein injection or intrauterine injection significantly elevated the numbers of endometrial glands and decreased the fibrosis area rate $(P<0.05$ vs Model). Moreover, both ER and PR were remarkably up-regulated after BMSCs transplantation $(P<0.05$ vs Model). The therapeutic effect attained to optimal level 1 or 2 weeks after transplantation. Conclusion: BMSCs transplantation was effective to repair the damaged endometrium likely through promoting the ER and PR expressions.

\section{Introduction}

Intrauterine adhesion (IUA), also known as Asheman syndrome is a disease caused by injury of endometrial basal layer due to endometrial fibrosis. Both of uterine cavity surgery and infection could cause partial or complete blockage of palace cavity, finally leading to abnormal menstruation, infertility and pregnancy abnormalities. Nowadays, there are still 


\section{Cellular Physiology Cell Physiol Biochem 2016;39:1553-1560

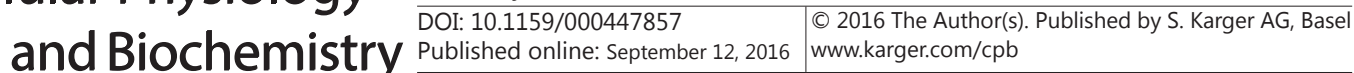 \\ Wang et al.: MSCs for Intrauterine Adhesions Treatment}

no effective therapeutic methods to treat this disease owning to the unknown mechanism [1-3].

Bone marrow mesenchymal stem cells (BMSCs) are one type of adult stem cells with the characteristics of self-renewal, multipotential differentiation, autotransplantation without immune rejection [4-6]. It is now of wide concern to repair the injured tissues by using BMSCs. After transplantation, BMSCs can migrate and accumulate in endometrial tissue. A clinical research also implicated that intrauterine transplantation of autologous bone marrow derived mesenchymal stem cells were beneficial for the regeneration of injured endometrium [7]. However, the specific mechanism still requires further investigation [812]. In this study, fluorescently labeled BMSCs were transplanted into IUA animal model and we aimed to observe the migration of BMSCs and the morphological changes of endometrium and determine the mechanisms.

\section{Materials and Methods}

\section{Animals}

Female Sprague Dawley rats (8-10 weeks, body weight $240 \pm 20$ g) were obtained from Animal Center of the Second Hospital, Tianjin Medical University. All the animals were raised in a specific-pathogenfree system with the temperature of $20-26{ }^{\circ} \mathrm{C}$, humidity of $50 \%-60 \%$ and $12 \mathrm{~h} / 12 \mathrm{~h}$ dark/light. All the experimental protocols were approved by the Ethics Committee of Tianjin Medical University.

\section{Isolation and culture of BMSCs}

BMSCs were isolated as previously described with minor modification (10). The rats were killed by cervical dislocation and soaked in $75 \%$ alcohol for $1 \mathrm{~min}$. Bilateral femur were isolated and washed by precold phosphate-buffered saline (PBS) twice. Bone marrow cavity was washed by low glucose Dulbecco's Modified Eagle's Medium containing $100 \mathrm{U} / \mathrm{ml}$ heparin without serum. The cells were re-suspended in low glucose DMEM with $10 \%$ fetal bovine serum, $100 \mathrm{U} / \mathrm{ml}$ penicillin and streptomycin at $37{ }^{\circ} \mathrm{C}$ and $5 \% \mathrm{CO}_{2}$. The cells were distinguished by flow cytometry with the antibodies of CD90, CD44 and CD45. Adipogenic differentiation induced by inducers (1 mM dexamethasone, $10 \mathrm{mg} / \mathrm{L}$ insulin, $50 \mathrm{mM}$ 3-isobutyl1-methylxanthine, $0.2 \mathrm{mM}$ indomethacin) was evaluated by Oil Red-0-staining. Osteogenic differentiation induced by inducers (1 mM dexamethasone, $1 \mathrm{M}$ sodium glycerol phosphate, $50 \mathrm{mM}$ Vitamin $\mathrm{C}$ ) was determined by alizarin red staining. The third generation of BMSCs was selected for the transplantation. $24 \mathrm{~h}$ before transplantation, BMSCs were transfected by lentivirus to express green fluorescence protein (MOI=50).

\section{Establishment of rat uterine cavity adhesion model}

Intravenous transplantation has been the standard method of BMSCs transplantation, but intrauterine transplantation has been recently reported as another beneficial way of transplantation [7]. Therefore, in this study, 48 rats were randomly divided into four groups: control, model, BMSCs vein injection and intrauterine therapy ( $\mathrm{n}=12$ in each group). Three rats were killed at time $0 \mathrm{~h}, 7 \mathrm{~d}, 14 \mathrm{~d}$ and $28 \mathrm{~d}$ and bilateral uterus were obtained at each time points for the following experiments. The control rats were not modeled and received the similar volume of vehicle. Rats in model group received mechanical damage. BMSCs vein injection group received both of mechanical damage and BMSCs vein injection. After modeling, the rats immediately received the third generation of BMSCs. The intrauterine therapy group received the BMSCs treatment at the uterine. After therapy, the rats were killed and the bilateral uterines were collected for hematoxylin-eosin staining (HE), Masson and immunohistochemical staining.

Rat uterine cavity adhesion model was established by using mechanical damage method. Briefly, after anesthesia with $4 \%$ chloral hydrate $(0.5 \mathrm{ml} / 100 \mathrm{~g}$, i.p.). The abdominal cavity was opened to expose the uterus and $2 \mathrm{~mm}$ transverse incision in the uterus was prepared at the upper end. A endometrial scraping spoon was applied to scrap bilateral intact endometrial to obtain a rough feeling.

\section{HE staining}

The tissues underwent regular paraffin embedding, section $(4 \mu \mathrm{m})$ and HE staining. The morphological changes were observed under the light microscope. Five fields in each image were selected for counting. 


\section{Cellular Physiology Cell Physiol Biochem 2016;39:1553-1560 \begin{tabular}{l|l|l} 
and Biochemistry $\begin{array}{l}\text { DOI: 10.1159/000447857 } \\
\text { Published online: September 12, } 2016\end{array}$ & $\begin{array}{l}\text { (c) } 2016 \text { The Author(s). Published by S. Karger AG, Basel } \\
\text { www.karger.com/cpb }\end{array}$
\end{tabular} \\ Wang et al.: MSCs for Intrauterine Adhesions Treatment}

\section{Masson staining}

The slices were also stained by Masson method. IPP software was applied to analyze the area of interstitial fibrosis of the endometrium and total area of the endometrial stroma and glands.

\section{Immunohistochemistry}

The immunohistochemistry of ER and PR expressions were conducted following the previous publication [13]. The primary antibodies against ER (1:200) and PR (1:200) were from Abcam (USA). After staining, the samples were observed under microscope. Light yellow, brown yellow or dark brown was supposed as the positive expression. Five fields from each image were selected for quantification. Based upon the density of staining and also the positive stained cell numbers, the expression of ER and PR were calculated. The expression was divided into strong, medium and weak grades. Different scores $(0,1,2,3)$ were ascribed to negative, weak, medium and high expression. The positive rate of the expression was also calculated: 1 (1\%-20\%), 2 (21\%-50\%), 3 (51\%-70\%) and 4 (71\%-100\%). The scores calculated based upon two methods were averaged. Finally, 0-1 was supposed as negative expression (-), 1-2 as weak expression $( \pm), 2-3$ as medium expression $(+)$ and 3-4 as high expression $(++)$.

\section{Statistical analyses}

All the data were presented as mean and standard deviation (SD) and analyzed by SPSS 17.0. Quantitative data between two groups were analyzed by $t$ test. The counting data were analyzed by $\chi 2$. Homogeneity of variance was tested in all the groups and single factor variance analysis (ANOVA) was applied to compare the difference among groups. $\mathrm{P}<0.05$ was considered as statistical significance.

\section{Results}

\section{Effects of BMSCs transplantation on morphological changes of endometrium}

The growth characteristics of BMSCs were shown in Figure 1A and 1B. BMSCs were identified by flow cytometry with the antibodies (CD44, CD90 and CD45) (Fig. 1C). The positive expressions of CD44, CD90, but not CD45 were applied as the makers for BMSCs. GFP was applied to label the transplanted BMSCs (Fig. 1D). Adipogenic and osteogenic

Fig. 1. BMSCs indentification. (A) The images of the BMSCs at the third day after isolation at the third generation. (B) The growth curve of BMSCs. (C) The staining of CD44, CD90 and CD45 detected by flow cytometry. (D) BMSCs binding with GFP. (E) Alizarin red staining and Oil Red-O staining indicated osteogenic and adipogenic differentiation.

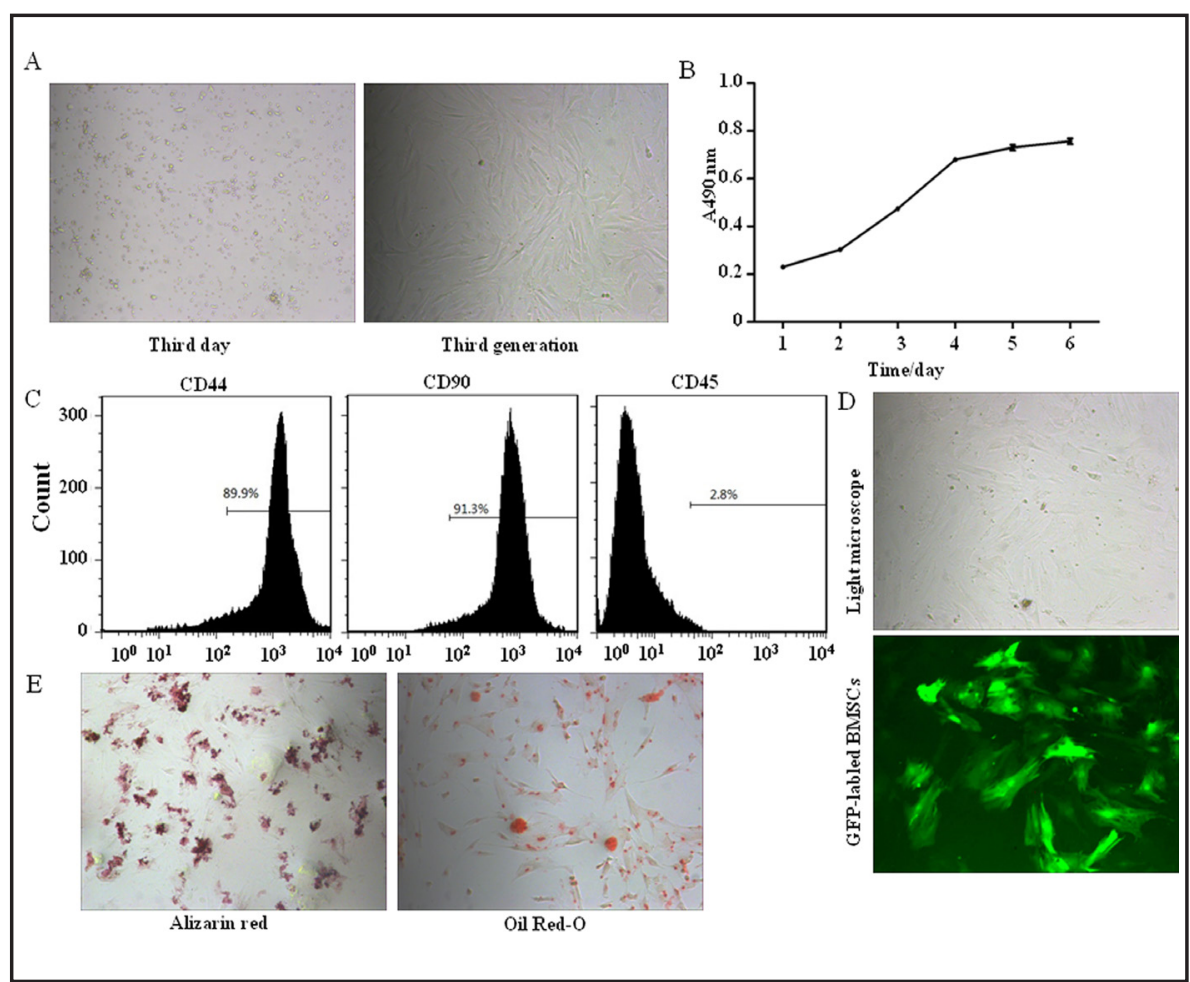




\section{Cellular Physiology Cell Physiol Biochem 2016;39:1553-1560

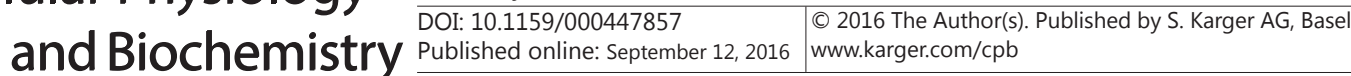

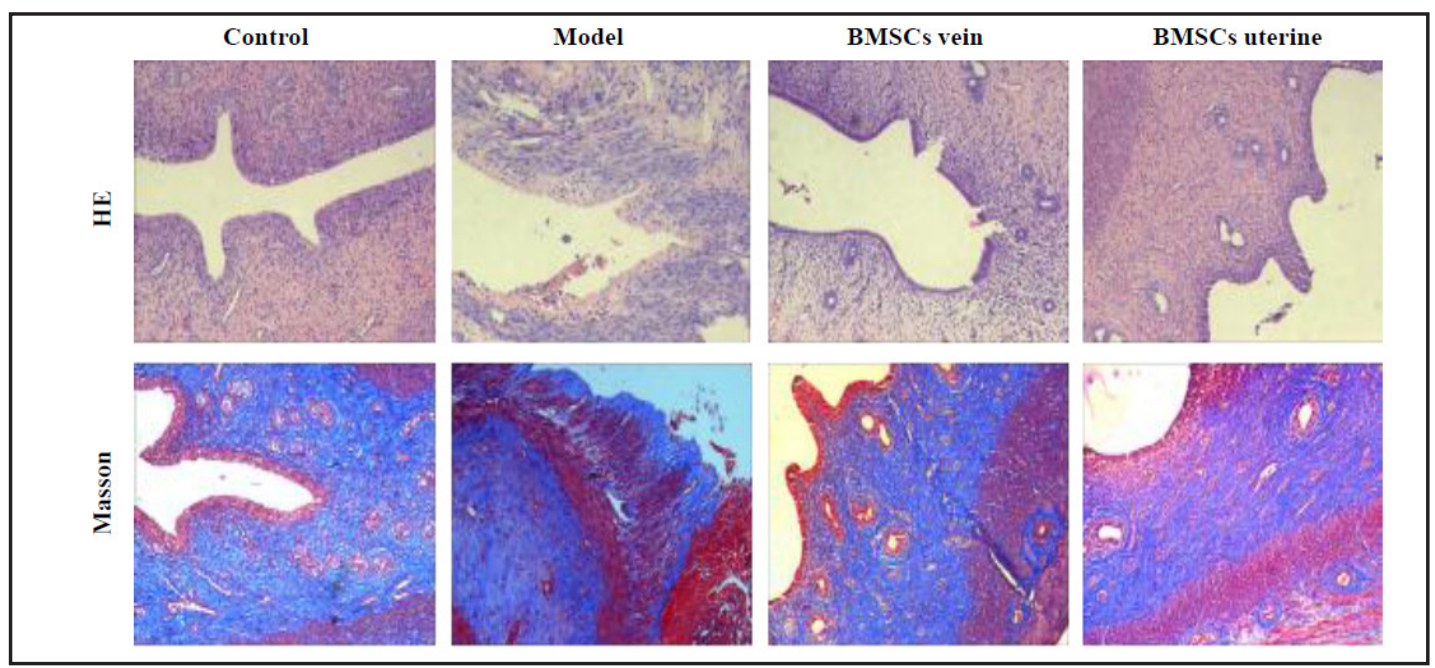

Fig. 2. Morphological changes of endometrium after BMSCs transplanatation in IUA rats. Upper panels were the HE staining. Down panels were the masson staining.

Table 1. The numbers of endometrial glands in each group (Numbers/

HP). $\# \mathrm{P}<0.05$ compared with control, ${ }^{*} \mathrm{P}<0.05$ compared with model

\begin{tabular}{lccccccc}
\hline Groups & $\mathrm{N}$ & Before treatment & $1 \mathrm{w}$ after & $2 \mathrm{w}$ after & $4 \mathrm{w}$ after & $\mathrm{F}$ & $\mathrm{P}$ \\
\hline Control & 12 & $13.67 \pm 0.52$ & $13.83 \pm 0.75$ & $13.50 \pm 0.55$ & $14.00 \pm 0.63$ & 0.72 & 0.55 \\
Model & 12 & $3.83 \pm 0.75$ & $4.50 \pm 0.55$ & $5.12 \pm 0.98$ & $5.67 \pm 0.52$ & 7.28 & $<0.01 \#$ \\
BMSCs vein & 12 & $4.00 \pm 0.89$ & $7.50 \pm 0.55$ & $10.33 \pm 1.03$ & $12.50 \pm 0.84$ & 74.31 & $<0.01^{*}$ \\
BMSCs uterine & 12 & $3.67 \pm 0.82$ & $7.33 \pm 1.21$ & $10.17 \pm 1.33$ & $12.33 \pm 1.37$ & 61.69 & $<0.01^{*}$ \\
\hline
\end{tabular}

Table 2. Fibrosis area rate in each group (\%). \#P<0.05 compared with control, $* \mathrm{P}<0.05$ compared with model

\begin{tabular}{lccccccc}
\hline Groups & $\mathrm{N}$ & Before treatment & $1 \mathrm{w}$ after & $2 \mathrm{w}$ after & $4 \mathrm{w}$ after & $\mathrm{F}$ & $\mathrm{P}$ \\
\hline Control & 12 & $23.00 \pm 1.79$ & $23.33 \pm 1.37$ & $23.17 \pm 0.98$ & $23.50 \pm 0.84$ & 0.17 & 0.92 \\
Model & 12 & $58.33 \pm 5.32$ & $53.50 \pm 5.47$ & $48.50 \pm 5.45$ & $47.50 \pm 5.39$ & 5.11 & $<0.01^{\#}$ \\
BMSCs vein & 12 & $57.67 \pm 5.01$ & $40.83 \pm 2.64$ & $29.67 \pm 1.75$ & $24.17 \pm 1.72$ & 137.8 & $<0.01^{*}$ \\
BMSCs uterine & 12 & $57.50 \pm 4.42$ & $41.33 \pm 2.07$ & $28.50 \pm 2.07$ & $23.50 \pm 1.52$ & 182.2 & $<0.01^{*}$ \\
\hline
\end{tabular}

differentiation abilities were confirmed by Oil Red-0-staining and alizarin red staining (Fig. $1 \mathrm{E})$. The transfection rate attained to $80 \%$ in our study.

Morphological changes of endometrium were indicated by HE and Masson staining (Fig. 2). In normal control groups, the endometrial cavity surface was covered by columnar epithelium with abundant endometrial glands. Stromal blue collagen fibers were rarely observed, but regularly arranged. In the model group, uterine endometrial glands were remarkably reduced with tissue hyperplasia (Table 1). Masson staining demonstrated that in model group a lot of stromal blue collagen fibers were found which were tightly arranged. Before treatment, the levels of endometrial glands, fibrosis area rate were statistically significant between control group and other groups $(\mathrm{P}<0.05)($ Table 2). By contrast, the endometrial glands in BMSCs vein injection group and uterine injection group were starting to increase after treatment. Newly- formed glands showed round or oval morphology. Masson staining showed that stromal blue collagen fibers after treatment were decreased to some extent. Moreover, with the extension of treatment time, the endometrium gradually recovered. Significant differences were observed 2 weeks and 4 weeks after treatment $(P$ $<0.05$ vs treatment before). However, there was no difference between 4 -week treatment 
Fig. 3. Uterine staining of GFP after BMSCs transplanatation.

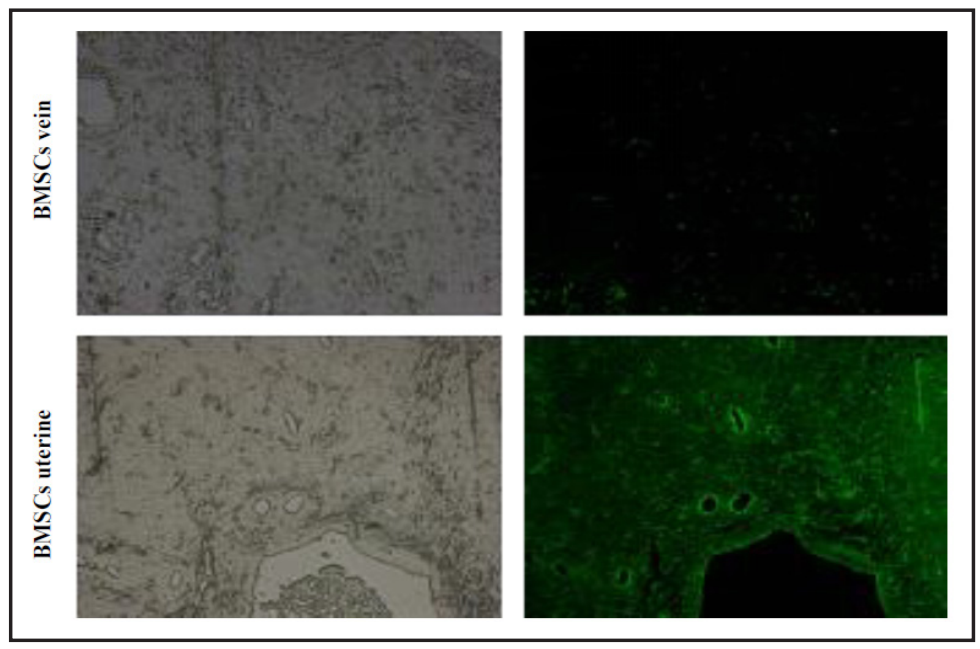

Fig. 4. ER and PR staining after BMSCs transplanatation in IUA rats.

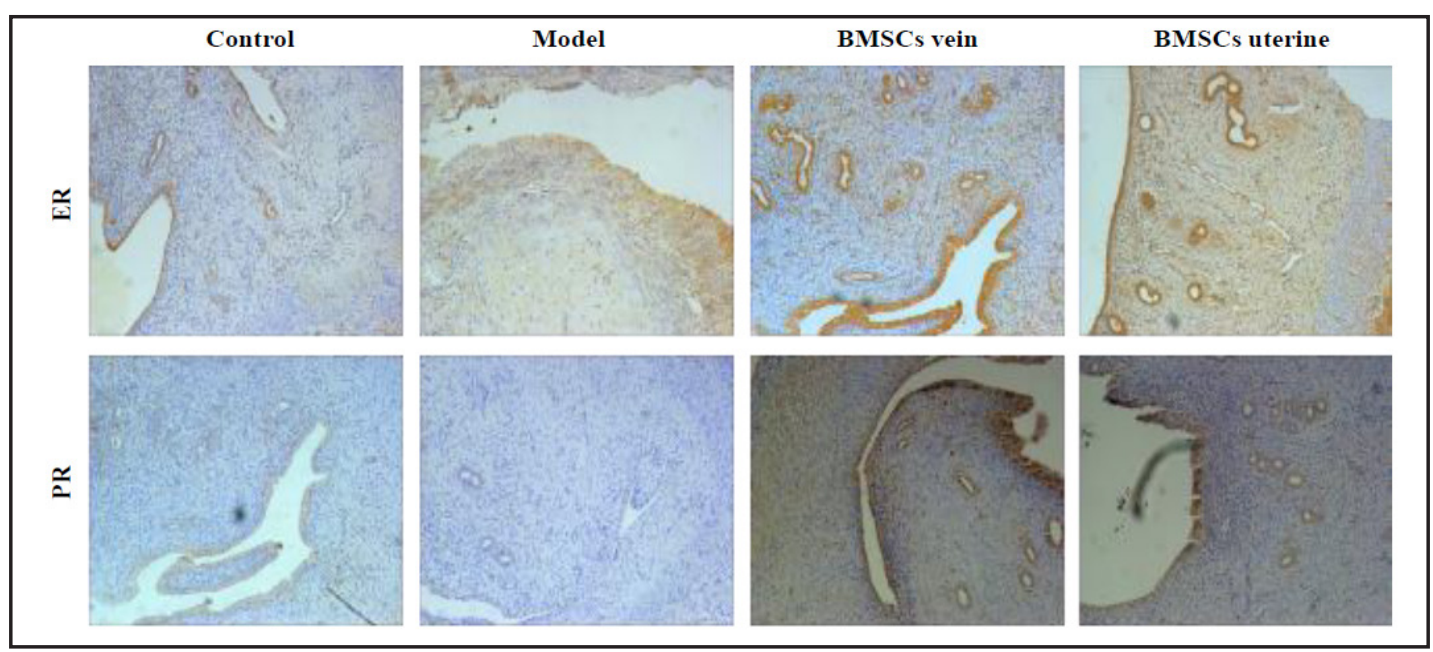

Table 3. ER and PR expressions in different locations

\begin{tabular}{lcccccccccc}
\hline Groups & \multicolumn{3}{c}{$\begin{array}{c}\text { ER } \\
\text { Positive rate } \\
(\%)\end{array}$} & $\chi^{2}$ & P & \multicolumn{3}{c}{$\begin{array}{c}\text { PR } \\
\text { Positive rate } \\
(\%)\end{array}$} & $\chi^{2}$ & P \\
\hline Gland cells & 16 & 34 & 68 & \multirow{2}{*}{5.844} & 0.016 & 19 & 31 & 62 & 4.006 & 0.045 \\
Mesenchyme & 28 & 22 & 44 & & & 29 & 21 & 42 & & \\
\hline
\end{tabular}

Table 4. ER and PR expressions in different groups. \#P<0.05 compared with control; ${ }^{*} \mathrm{P}<0.05$ compared with model

\begin{tabular}{lccccccc}
\hline Groups & $\mathrm{N}$ & $\mathrm{ER}$ & $\mathrm{t}$ & $\mathrm{P}$ & $\mathrm{PR}$ & $\mathrm{t}$ & $\mathrm{P}$ \\
\hline Control & 6 & $3.03 \pm 0.20$ & & & $2.07 \pm 0.11$ & & \\
Model & 6 & $3.92 \pm 0.20$ & $3.14^{\#}$ & $0.011^{*}$ & $2.03 \pm 0.10$ & $0.23^{\#}$ & $0.824^{\#}$ \\
BMSCs i.v. & 6 & $5.10 \pm 0.25$ & $3.69^{*}$ & $0.004^{*}$ & $2.97 \pm 0.15$ & $5.15^{*}$ & $<0.001^{*}$ \\
BMSCs uterine & 6 & $5.23 \pm 0.26$ & $4.04^{*}$ & $0.002^{*}$ & $3.03 \pm 0.12$ & $6.43^{*}$ & $<0.001^{*}$ \\
\hline
\end{tabular}

and 2-week treatment $(\mathrm{P}=0.226)$. BMSCs labeled by green fluorescence protein were also observed in rat endometrium in both treatment groups (Fig. 3). 


\section{Cellular Physiology Cell Physiol Biochem 2016;39:1553-1560 \\ \begin{tabular}{ll|l} 
and Biochemistry Published online: September 12, 2016 & $\begin{array}{l}\text { (c) } 2016 \text { The Author(s). Published by S. Karger AG, Basel } \\
\text { www.karger.com/cpb }\end{array}$ \\
\hline
\end{tabular} \\ Wang et al.: MSCs for Intrauterine Adhesions Treatment}

\section{BMSCs therapies promote ER and PR expressions}

ER and PR expressions were detected by immunohistochemistry (Fig. 4). In control group, the positive rates of ER expression in gland cells and in mesenchyme were $68 \%$ and $44 \%$, respectively (Table 3 ). The positive rate of PR in gland cells and mesenchyme were $62 \%$ and $42 \%$, respectively. When comparing the ER expression in different groups, we found ER expression in model group was remarkably higher than that in control group (Table 4). PR expression was significantly different between control and model groups. BMSCs vein injection or uterine injection not only significantly elevated ER expressions ( $p<0.05$ vs control or model), but also PR expression ( $\mathrm{p}<0.05$ vs control or model).

\section{Discussion}

Intrauterine adhesion is a severe disease affecting menstrual and reproduction. In 1948, Asherman described the specific details of the uterine cavity adhesion. Therefore, uterine cavity adhesion related clinical manifestation was also named as Asherman syndrome [1416]. The uterine cavity adhesion was indicated by fibrosis, sparsely glandular, inactive or cystic dilatation and ischemic injury. Approximately, 50\% of the uterine cavity adhesion patients displayed infertility. Therefore, more attention has been paid to this severe disease. Hysteroscopic adhesiolysis is considered to be the gold standard in the treatment of intrauterine adhesions and has been widely applied in clinic. However, the high recurrence rate after surgery disturbed the application and effective treatment was still required [1-3, $14,17,18]$.

BMSCs were found in bone marrow with the advantages of convenient harvest and abundant supplements. Moreover, the application of BMSCs could avoid the self-immune rejection. Marrow mesenchymal stem cells (MSCs) were famous for their abilities of self-renewal, and multi-differentiation. Therefore, BMSCs were supposed as the ideal candidate cells for transplantation and widely applied in tissue repairing [8, 19-22]. BMSCs transplantation could be applied to treat a variety of diseases caused by injury, including cerebral ischemia, myocardial infarct, etc [23]. The investigations implicated that BMSCs could migrate to and accumulate in endometrial tissue. That would thicken the endometrial, and improve endometrial receptivity. Therefore, BMSCs transplantation was thought to have the potential to treat thin endometrium [24-27]. In 2011, scientists reported for the first time that BMSCs could be applied to treat severe intrauterine adhesion. Later, the research team also applied stem cell therapy to treat 6 cases with refractory uterus cavity adhesions. Among them, 5 cases received endometrial MSCs injection $[10,28]$. These evidences indicated that exogenous mesenchymal stem cells played positive roles in repairing the endometrium. In our study, the application of BMSCs through two different methods was compared. Although vein injection of BMSCs was effective in the treatment, intrauterine injection demonstrated a better efficacy. These results implicate a new method to deliver BMSCs in the treatment of IUA.

In our study, BMSCs were isolated and cultured in vitro. Moreover, GFP was connected to BMSCs to indicate the uterine migration. We established uterine cavity adhesion model in $\mathrm{SD}$ rats and injected the BMSCs through either vein or intrauterine. Although both methods were reported to be effective to deliver BMSCs, we found that the live BMSCs in uterine were more abundant in uterine injection group than that in vein injection group. That might indicated that local injection of BMSCs was more effective to treat diseases.

ER and PR are critical factors mediating the reproductive activity [29]. These two factors are extensively expressed in whole layers of uterus. After binding to estrogen or progesterone, the signaling transduction at the downstream of ER and PR were activated to initiate the gene expression and cell differentiation to maintain the uterus function [30]. IUA is a disease characterized by the injury of basal layer of endometrium caused by mechanical injury or infection. In addition, the vessel repairing mechanism was also impaired in IUA [31]. To this end, the response ability of endometrial cells to estrogen was reduced in IUA. This would lead 


\section{Cellular Physiology Cell Physiol Biochem 2016;39:1553-1560 \begin{tabular}{l|l|l|}
\hline DOI: 10.1159/000447857 & $\begin{array}{l}\text { C) 2016 The Author(s). Published by S. Karger AG, Basel } \\
\text { www.karger.com/cpb }\end{array}$
\end{tabular} \\ Wang et al.: MSCs for Intrauterine Adhesions Treatment}

to the reduction of complex of estrogen with its receptors and the endometrial receptivity. Therefore, the ER and PR are the critical targets for the treatment of IUA. In our study, ER was remarkably up-regulated in the BMSCs therapy groups compared with control or model groups. Moreover, the ER expression was abundantly expressed in endometrial glands, but not in endometrial stroma. By contrast, PR was slightly up-regulated after BMSCs therapies. These data suggested that BMSCs therapy rapidly promoted the newly-formed endometrial glands and replaced the fibrosis cicatrix, in turn increasing ER and PR expression. Finally, the endometrial receptivity was increased due to the up-regulated ER and PR. In addition, our study also implicated that supplement of physiological doses of estrogen or progesterone was beneficial for the repairing of uterus.

We reported the application of BMSCs in the treatment of IUA in the animal model. However, due to the differences between humans and rats, whether it could be apply in clinical practice still requires more investigations. In addition, more deeply mechanisms would guarantee the future application of BMSCs in the treatment of IUA.

\section{Conclusions}

In this study, we provide a stem cell therapy method for IUA that both of tail vein injection and intrauterine application showed treatment efficacy. In addition, we provided novel evidence that ER and PR could be involved in the treatment.

\section{Acknowledgements}

This study was funded by Tianjin Sanitary Bureau Scientific funding (2012KZ093).

\section{Disclosure Statement}

The authors declare they have no competing interests.

\section{References}

1 Yu D, Wong YM, Cheong Y, Xia E, Li TC: Asherman syndrome--one century later. Fertil Steril 2008;89:759779.

2 Zupi E, Centini G, Lazzeri L: Asherman syndrome: an unsolved clinical definition and management. Fertil Steril 2015;104:1380-1381.

3 March CM: Management of Asherman's syndrome. Reprod Biomed Online 2011;23:63-76.

$4 \quad$ Jia S, Liu X, Li W, Xie J, Yang L, Li L: Peroxisome Proliferator-Activated Receptor Gamma Negatively Regulates the Differentiation of Bone Marrow-Derived Mesenchymal Stem Cells Toward Myofibroblasts in Liver Fibrogenesis. Cell Physiol Biochem 2015;37:2085-2100.

5 Tang L, Chen Y, Pei F, Zhang H: Lithium Chloride Modulates Adipogenesis and Osteogenesis of Human Bone Marrow-Derived Mesenchymal Stem Cells. Cell Physiol Biochem 2015;37:143-152.

6 Song BQ, Chi Y, Li X, Du WJ, Han ZB, Tian JJ, Li JJ, Chen F, Wu HH, Han LX, Lu SH, Zheng YZ, Han ZC: Inhibition of Notch Signaling Promotes the Adipogenic Differentiation of Mesenchymal Stem Cells Through Autophagy Activation and PTEN-PI3K/AKT/mTOR Pathway. Cell Physiol Biochem 2015;36:1991-2002.

7 Santamaria X, Cabanillas S, Cervello I, Arbona C, Raga F, Ferro J, Palmero J, Remohi J, Pellicer A, Simon C: Autologous cell therapy with CD133+ bone marrow-derived stem cells for refractory Asherman's syndrome and endometrial atrophy: a pilot cohort study. Hum Reprod 2016;31:1087-1096.

8 Ren G, Chen X, Dong F, Li W, Ren X, Zhang Y, Shi Y: Concise review: mesenchymal stem cells and translational medicine: emerging issues. Stem Cells Transl Med 2012;1:51-58. 


\section{Cellular Physiology Cell Physiol Biochem 2016;39:1553-1560 \begin{tabular}{l|l|l} 
and Biochemistry & Dublished 10.1159/000447857 & $\begin{array}{l}\text { C } 2016 \text { The Author(s). Published by S. Karger AG, Basel } \\
\text { www.karger.com/cpb }\end{array}$
\end{tabular} \\ Wang et al.: MSCs for Intrauterine Adhesions Treatment}

9 Dominici M, Le Blanc K, Mueller I, Slaper-Cortenbach I, Marini F, Krause D, Deans R, Keating A, Prockop D, Horwitz E: Minimal criteria for defining multipotent mesenchymal stromal cells. The International Society for Cellular Therapy position statement. Cytotherapy 2006;8:315-317.

10 Jing Z, Qiong Z, Yonggang W, Yanping L: Rat bone marrow mesenchymal stem cells improve regeneration of thin endometrium in rat. Fertil Steril 2014;101:587-594.

11 Xiao WL, Zhang DZ, Fan CH, Yu BJ: Intermittent Stretching and Osteogenic Differentiation of Bone Marrow Derived Mesenchymal Stem Cells via the p38MAPK-Osterix Signaling Pathway. Cell Physiol Biochem 2015;36:1015-1025.

12 Zhang Z, Zhang T, Zhou Y, Wei X, Zhu J, Zhang J, Wang C: Activated phosphatidylinositol 3-kinase/Akt inhibits the transition of endothelial progenitor cells to mesenchymal cells by regulating the forkhead box subgroup 0-3a signaling. Cell Physiol Biochem 2015;35:1643-1653.

13 Wu S, Cao J, Zhang T, Zhou Y, Wang K, Zhu G, Zhou M: Electroacupuncture Ameliorates the Coronary Occlusion Related Tachycardia and Hypotension in Acute Rat Myocardial Ischemia Model: Potential Role of Hippocampus. Evid Based Complement Alternat Med 2015;2015:925987.

14 Deans R, Abbott J: Review of intrauterine adhesions. J Minim Invasive Gynecol 2010;17:555-569.

15 Schenker JG, Margalioth EJ: Intrauterine adhesions: an updated appraisal. Fertil Steril 1982;37:593-610.

16 March CM: Asherman's syndrome. Semin Reprod Med 2011;29:83-94.

17 Tsui KH, Lin LT, Cheng JT, Teng SW, Wang PH: Comprehensive treatment for infertile women with severe Asherman syndrome. Taiwan J Obstet Gynecol 2014;53:372-375.

18 Hooker AB, Lemmers M, Thurkow AL, Heymans MW, Opmeer BC, Brolmann HA, Mol BW, Huirne JA: Systematic review and meta-analysis of intrauterine adhesions after miscarriage: prevalence, risk factors and long-term reproductive outcome. Hum Reprod Update 2014;20:262-278.

19 Figueroa FE, Carrion F, Villanueva S, Khoury M: Mesenchymal stem cell treatment for autoimmune diseases: a critical review. Biol Res 2012;45:269-277.

20 Yagi H, Soto-Gutierrez A, Parekkadan B, Kitagawa Y, Tompkins RG, Kobayashi N, Yarmush ML: Mesenchymal stem cells: Mechanisms of immunomodulation and homing. Cell Transplant 2010;19:667-679.

21 Fossett E, Khan WS: Optimising human mesenchymal stem cell numbers for clinical application: a literature review. Stem Cells Int 2012;2012:465259.

22 Zhang J, Wu Y, Chen A, Zhao Q: Mesenchymal stem cells promote cardiac muscle repair via enhanced neovascularization. Cell Physiol Biochem 2015;35:1219-1229.

23 Wu J, Niu J, Li X, Li Y, Wang X, Lin J, Zhang F: Hypoxia induces autophagy of bone marrow-derived mesenchymal stem cells via activation of ERK1/2. Cell Physiol Biochem 2014;33:1467-1474.

24 Alawadhi F, Du H, Cakmak H, Taylor HS: Bone Marrow-Derived Stem Cell (BMDSC) transplantation improves fertility in a murine model of Asherman's syndrome. PLoS One 2014;9:e96662.

25 Du H, Taylor HS: Contribution of bone marrow-derived stem cells to endometrium and endometriosis. Stem Cells 2007;25:2082-2086.

26 Ikoma T, Kyo S, Maida Y, Ozaki S, Takakura M, Nakao S, Inoue M: Bone marrow-derived cells from male donors can compose endometrial glands in female transplant recipients. Am J Obstet Gynecol 2009;201:608 e601-608.

27 Gargett CE, Schwab KE, Zillwood RM, Nguyen HP, Wu D: Isolation and culture of epithelial progenitors and mesenchymal stem cells from human endometrium. Biol Reprod 2009;80:1136-1145.

28 Nagori CB, Panchal SY, Patel H: Endometrial regeneration using autologous adult stem cells followed by conception by in vitro fertilization in a patient of severe Asherman's syndrome. J Hum Reprod Sci 2011;4:43-48.

29 Andersson A, Bernardi AI, Nurkkala-Karlsson M, Stubelius A, Grahnemo L, Ohlsson C, Carlsten H, Islander U: Suppression of Experimental Arthritis and Associated Bone Loss by a Tissue-Selective Estrogen Complex. Endocrinology 2016;157:1013-1020.

30 Su RW, Strug MR, Jeong JW, Miele L, Fazleabas AT: Aberrant activation of canonical Notch1 signaling in the mouse uterus decreases progesterone receptor by hypermethylation and leads to infertility. Proc Natl Acad Sci U S A 2016;113:2300-2305.

31 Chen Y, Chang Y, Yao S: Role of angiogenesis in endometrial repair of patients with severe intrauterine adhesion. Int J Clin Exp Pathol 2013;6:1343-1350. 